\title{
Review \\ Prophylactic HPV vaccines: prospects for eliminating ano-genital cancer
}

\author{
M Stanley*,1 \\ 'Department of Pathology, University of Cambridge, Tennis Court Road, Cambridge CB2 I QP, UK
}

Virtually all cases of cervical cancer and its precursor intra-epithelial lesions are a result of infection with one or other of a subset of genital human papillomaviruses (HPVs), suggesting that prevention of HPV infection by prophylactic vaccination would be a highly effective anticancer strategy. Two HPV LI virus-like particle vaccines have been developed, a quadrivalent HPVI6/I8/6/II product and a bivalent HPVI6/I8 product; both have been shown to be highly immunogenic with a good safety profile and I00\% efficacy against HPVI6/I 8-related high-grade cervical intra-epithelial neoplasia (CIN2/3), implying that they will be effective at preventing HPV 16/18-related cervical cancer.

British Journal of Cancer (2007) 96, I320-1323. doi:10.1038/sj.bjc.6603695 www.bjcancer.com

Published online 20 March 2007

(c) 2007 Cancer Research UK

Keywords: vaccines; HPVI6/I8 LI VLPs; neutralising antibody; cervical cancer; CIN2/3; protection

Papillomaviruses are a large family of small, double-stranded DNA viruses that cause benign epithelial proliferations or warts in the natural infection. These viruses have two key characteristics; first they are absolutely host-specific, thus rabbit viruses only infect rabbits, dog viruses only infect dogs, human papillomaviruses (HPVs) only infect humans, secondly they are tissue-specific, a complete infectious cycle occurs only in a fully differentiating keratinised squamous epithelium. The HPVs are a very large family, classified by genotype (DNA sequence) not by serotype. To date, at least $200 \mathrm{HPVs}$ have been isolated from tissue biopsies and, of these, approximately 100 have been fully sequenced. Despite their very large numbers, HPVs can be classified into two large groups: those that infect skin, or cutaneous surfaces, and those that infect the internal wet-squamous mucosal surfaces. Within these groups there are low-risk types, which generate benign lesions, in other words, warts, and high-risk or oncogenic types, which are associated with cancers and their precursor lesions.

This is particularly apparent in the genital tract, where approximately $40 \mathrm{HPV}$ types regularly or sporadically infect the mucosal epithelial surfaces. Low-risk HPV types, HPV6 and 11 cause more than $90 \%$ of genital warts with minor types (HPV42, -44) and some high-risk HPVs contributing to about $10 \%$. Oncogenic HPVs in the genital tract are dominated by HPV16 and HPV18 which, with their close relatives, $31,33,35,52,58,39$, $45,59,56,66$ and 51, are the cause of cervical cancer (Clifford et al, 2003). Thus in $99 \%$ or more of biopsies of invasive cervical cancer worldwide, HPV DNA sequences can be detected (Walboomers et al, 1999), and in the high-risk precursor lesions, cervical intraepithelial neoplasia (CIN2, -3) approximately $80 \%$ contain the high-risk HPVs (Clifford et al, 2003). HPV16 dominates, with at

*Correspondence: Professor M Stanley; E-mail: mas@mole.bio.cam.ac.uk Received 3 January 2007; revised 13 February 2007; accepted 23 February 2007; published online 20 March 2007 least $50 \%$ of cancers irrespective of geographical location, containing HPV16, followed by HPV18, 7 to $20 \%$. Human papillomavirus infection is not only the cause of invasive cervical cancer and hrDNA sequences are found in a proportion of anal, vulvar, vaginal, penile and head and neck cancers (Table 1). HPV16 is the dominant oncogenic type followed by HPV18 and overall, the malignant burden attributable to HPV infection is calculated to be $3.71 \%$ of all cancers (Parkin and Bray, 2006)

The natural history of cervical intraepithelial neoplasia CIN is, in effect, the natural history of HPV infection in the cervix. Transient genital HPV infections, both of high- and low-risk HPVs, are very common in young sexually active women with the lifetime risk for acquiring a genital HPV infection in the UK of the order of 70 to $80 \%$. Most of these infections are transient and resolve. If lesions develop, they are low-grade CIN1 and represent the infectious cycle of the virus and are, in fact, flat papillomas. However, a fraction of infected women (approximately 10 to $15 \%$ ) develop persistent HPV infection, and fail to clear virally infected cells possibly because of the failure to develop a strong cellmediated immune response to HPV early proteins. These persistent infections with oncogenic HPVs are at risk for progression to the high-grade precursor lesion $\mathrm{CIN} 2 / 3$ and approximately 30 to $40 \%$ of CIN $2 / 3$ then progress on to invasive carcinoma (Muñoz et al, 2006).

\section{HPV VACCINES}

Prophylactic vaccines have been and continue to be the most effective strategy for controlling viral infections and papillomaviruses should be no exception to this. The antibody response to HPV in humans is a serum neutralising antibody response to the major capsid protein L1. However, neutralising antibody titres are very low; the assay systems for detection of neutralising antibody are not particularly sensitive and not all infected individuals 
sero-convert (Carter et al, 2000). The evidence is that approximately $50 \%$ of women infected with HPV16 sero-convert; $70 \%$ sero-convert to HPV6. In men sero-conversion rates for HPV16 or 18 are not clearly known, but sero-conversion against HPV6 is found only in about $40 \%$ of men (Carter et al, 1995). Although neutralising antibody titres are low evidence from animal infections, including some of the earliest published works from Shope, the founding father of papillomavirus research (Shope, 1937), showed very clearly that neutralising antibody was protective. Thus if rabbits were infected systemically with the cotton tail rabbit papillomavirus (CRPV) by direct injection of virus into the muscle, papillomas did not arise in the infected animals but neutralising antibody was generated and the animals were completely resistant to viral challenge by abrasion of the epithelium. This and other data suggested very strongly that generating neutralising antibody to virus capsid protein would be an effective prophylactic vaccine strategy. Neutralising antibodies are directed against the L1 capsid protein and the generation of this antibody requires the tertiary or native structure of the protein. As these viruses cannot be grown in bulk in tissue culture and viral particles particularly of the oncogenic types are sparse in lesions, the generation of native structure, or properly folded L1 protein, was challenging. The challenge was met by the demonstration that if the L1 gene was expressed via a eukaryotic vector, such as yeast (Jansen et al, 1995) or baculovirus (Kirnbauer et al, 1992), the L1 protein was produced in large amounts and selfassembled into a macromolecular structure, a virus-like particle (VLP) an empty capsid that is geometrically and antigenically almost identical to the native virion. These VLPs were shown to generate neutralising antibody in the animal models and immunised animals were protected against high-level virus challenge (Jansen et al, 1995; Suzich et al, 1995; Kirnbauer et al, 1996).

Two HPV L1 VLP prophylactic vaccines have been developed, these are Cervarix ${ }^{\mathrm{TM}}$, a bivalent HPV16/18 VLP vaccine from GlaxoSmithKline Biologicals (Rixensart, Belgium), and Gardasil ${ }^{\mathrm{TM}}$ also know as Silgard, a quadrivalent HPV16/18/6/11 vaccine from Merck Vaccines (Merk \& Co Inc, Whitehouse Station, NJ, USA) (Table 2). Although the numbers are small, in the according-toprotocol (ATP)groups in the Phase II trial of Cervarix there was $100 \%$ efficacy against the development of HPV16/18-asscociated high-grade CIN2/3 (Harper et al, 2004, 2006). In the Phase III trials of the Gardasil, the vaccine was $100 \%$ effective at preventing HPV16/18 high-grade CIN2/3 and was $100 \%$ effective at preventing HPV6/11/16 or 18-related external genital disease, that is genital warts, vulval intra-epithelial neoplasia (VIN) and vaginal intraepithelial neoplasia (VAIN) (http: www.cdc.gov/nip/acip/slides/ jun06/hpv-2-barr.pdf; Villa et al, 2006), and this vaccine is now licensed in many countries including those of the European Union and the USA.

The assumption is that the neutralising antibody to L1 generated by VLP vaccines or, after exposure to virus in natural infections, provides protection but what is the evidence to support this? The most convincing evidence is from preclinical experiments in dogs and rabbits, in which passive transfer of purified immunoglobulin-G from hyper-immune donors immunised with CRPV L1 VLPs, or dogs after spontaneous regression of canine oral papillomavirus (COPV), completely protected the naïve rabbit or dog recipient from challenge with high viral innocula (Breitburd et al., 1995; Ghim et al, 2000). Only animals immunised with intact VLPs generated neutralizing antibody and only purified IgG from these animals protected the naïve recipients. However, the question does

Table I The burden of malignant disease attributable to HPV infection

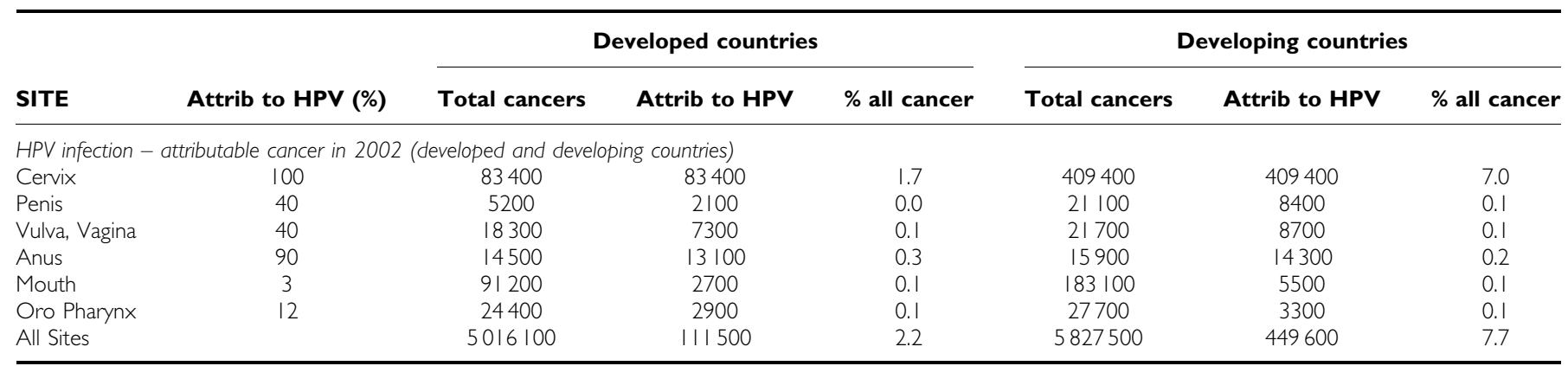

It is estimated that $70 \%$ of all cervix cancers irrespective of geographical region are owing to HPVI6/I8 (Parkin and Bray, 2006). The current prophylactic vaccines might be expected therefore to reduce the incidence of cervical cancer over the next several decades in unscreened populations by up to $70 \%$ depending upon vaccine coverage. In wellscreened populations the first effects would be a reduction in low-grade cervical abnormalities and CIN 3. It is estimated that up to $30 \%$ of low grade disease and $50 \%$ of CIN would be prevented in the vaccinated populations.

Table 2 HPV LI VLP vaccine profiles

\begin{tabular}{|c|c|c|}
\hline LI VLP Antigens & $\begin{array}{l}\text { HPV6 } 20 \mu \mathrm{g} \\
\text { HPV II } 40 \mu \mathrm{g} \\
\text { HPV } 1640 \mu \mathrm{g} \\
\text { HPV } 1820 \mu \mathrm{g}\end{array}$ & $\begin{array}{l}\text { HPVI6 } 20 \mu \mathrm{g} \\
\text { HPV } 1820 \mu \mathrm{g}\end{array}$ \\
\hline Expression system & Yeast (Saccharomyces cerevisiae) & Baculovirus \\
\hline $\begin{array}{l}\text { Adjuvant } \\
\text { Injection volume and immunisation schedule } \\
\text { Adolescent safety/immunogenicity bridging trials }\end{array}$ & $\begin{array}{l}\text { Proprietary aluminum hydroxyphosphate Sulfate } \\
(225 \mu \mathrm{g}) \\
0.5 \mathrm{ml} \text { i.m. 0, } 2 \text { and } 6 \text { months } \\
\text { Females and males } 9-15 \text { years } \\
\text { Licensed }\end{array}$ & $\begin{array}{l}\text { ASO4 aluminum hydroxide }(500 \mu \mathrm{g}) \text { plus } 50 \mu \mathrm{g} \\
3 \text {-deacylated monophosphoryl lipid A } \\
0.5 \mathrm{ml} \text { i.m. } 0,1 \text { and } 6 \text { months } \\
\text { Females } 10-14 \text { years } \\
\text { Males } 10-18 \text { years (in progress) } \\
\text { License application made }\end{array}$ \\
\hline
\end{tabular}

i.m. $=$ intramuscular 
remain as to how serum neutralising antibody protects against exclusively intra-epithelial infections of the cervix and lower genital tract mucosa and skin. A persuasive hypothesis has been that virus entry requires microtrauma to the epithelial surface and there is some recent evidence (J Roberts, personal communication) in an experimental model of infection that this can occur on infection with epithelial denudation but with the retention of a basement membrane, a scenario that would likely result in serous exudation and rapid access of serum IgGs to the virus particles. Furthermore, the portio surface of the cervix and the upper vaginal epithelium are bathed in cervical mucous, and the dominant immunoglobulin in cervical mucous is IgG transudated across the endo-cervical and squamo-columnar surfaces (Nardelli Haefliger et al, 2003). So, there is clearly rapid and easy access of serum antibody to the virus particles explaining the extraordinary efficacy of the VLP vaccines.

These vaccines are clearly remarkably efficacious in the short term but what is the duration of the protection induced by the vaccines? Will we need frequent booster vaccines? There is very encouraging data from both Phase II and Phase III trials showing that serum antibody levels fall from the peak levels achieved after the third immunisation to a lower concentration that persists at the same level for at least 60-months post-vaccination (Harper et al, 2006; Mao et al, 2006; Villa et al, 2006). The antibody concentrations in the plateau period in vaccinees are still 10 to 20 times that of natural infection. This data, combined with the evidence from large-scale population studies of naturally-infected individuals in which it can be shown that the antibody levels persist for at least 10 years after natural infection (af Geijersstam et al, 1999), leads to optimism that these vaccines will induce very long-lasting protection. The immune correlates of protection have so far not been established because all individuals in the trials appear to have sero-converted and there have been no evident vaccine breakthroughs.

The humoral immunity induced appears to be predominantly type-specific and this raises the question of whether there is any cross-protection afforded by the vaccines as there is considerable amino-acid sequence homology in L1 between closely related HPV types (Chen et al, 2000). There is evidence from the Phase II trial of Cervarix that HPV16/18 vaccinees are partially protected against incident infection with HPV31 and HPV45 (Harper et al, 2006). The possibility of cross-protection from the VLP vaccines is strengthened by the evidence that cross-reactive antibodies against HPV31/45/52 and 58 are generated after vaccination with Gardasil (Smith JV, personal communication) and, importantly, crossneutralising antibodies to HPV45 and 31 are generated after vaccination with this vaccine albeit at concentrations 1 to $2 \log$ lower than the dominant type-specific neutralising antibodies. It must be emphasised however that, at the present time, there is no evidence for cross-protection against HPV45 or 31 induced CIN2/3 and if such cross-protection does occur, it is likely to be partial and not complete. This does imply that second generation vaccines will need to include other HPV types and a frequently asked question is, will we need different 'cocktails' of HPV types for different populations. This seems unlikely. HPV16 and HPV18 are the dominant types worldwide consistently detected in $70 \%$ of all cervix cancers. A further six types, HPV45/31/56/52/35 and 33, consistently make up the remaining 20 to $30 \%$, irrespective of the geographic region and a polyvalent vaccine that contained these eight types would effectively protect against more than $90 \%$ of all cervix cancers (Clifford et al, 2006).

A question that is currently generating more heat than light is, who and when to vaccinate? HPV L1 VLP vaccines are prophylactic not therapeutic preventing, not treating infection, and the available evidence is clear that immunisation with them will not be effective in individuals with established HPV infections of the types included in the current vaccines. Genital HPV infection is usually, but not always, sexually transmitted and for effective population- based programmes, immunisation should precede the sexual debut and the target population for vaccination, should therefore be eleven to 12-year-old pre-pubertal girls. Immunologically this is the optimal time because the immune system 'ages' after puberty. Immunogenicity bridging studies from the quadrivalent vaccine looking at antibody concentrations achieved after immunisation in 9- to 15-year-old girls and boys have shown that antibody levels after HPV VLP vaccination are higher in 9- to 10-year-old girls than 13- to 15-year-old girls, and higher in 13- to 15-year-old girls than 16 to 23-year-old women. The levels are higher in 9- to 15year-old boys than in 9- to 15-year-old girls, suggesting that male immunisation will be effective (Block et al, 2006). Certainly if herd immunity against HPV is to be achieved, and virus transmission interrupted effectively, then boys, as well as girls, should be immunised. However, all the efficacy trials have included women only and there is no efficacy data in men available although trials are ongoing. The arguments against vaccinating boys against the oncogenic HPVs are based on health economic considerations and cost effectiveness. In a heterosexual population, the spread of HPV infection can be stopped entirely by complete protection of one sex alone and dynamic simulation models of HPV transmission show that if high coverage of females can be achieved, there is little to be gained in the additional reduction of cervical cancer by vaccinating males.

What about older women? Will these vaccines have any efficacy in women who are sexually active and who may have been exposed to HPV? The Phase III trials have shown that vaccination of HPV16 DNA-negative women - 16- to 23-year olds - does protect against the development of HPV16/18-related CIN2 or -3, implying that women in this age group, who are HPV16/18 DNA-negative, can be vaccinated with confidence, in that they will be protected against the development of 16/18-related disease. However, it is highly unlikely that there will be prescreening for HPV infection in any group, and sexually active women who are immunised would therefore have to continue in a cervical cancer screening programme, if that is available. The future of screening is another frequently raised topic, will these vaccines eliminate the need for cervical cancer screening programmes? The answer is, absolutely not in the short or medium term. It seems clear that if the current HPV prophylactic vaccines are introduced for mass immunisation in countries with effective cervical screening programmes, then the latter will have to continue unless significant cross-protection is induced by VLP immunisation to the extent that the protection against cervix cancer afforded by the vaccines is significantly greater than the prevention of cervical cancer achieved with the best population-based screening programmes, such as those in the UK. The cervical screening programme in England, at present, covers 80 to $82 \%$ of women at risk, and prevents $90 \%$ of cervical cancers in that group, with an overall protection from cervix cancer of the order of $76 \%$. To discontinue this cancer-screening programme would require the vaccines to achieve at least 85 to $90 \%$ prevention of cervical cancer. Even if immunisation with the current vaccines was introduced for the 11- to 12-year old cohort, both immunised and non-immunised population cohorts would have continued in a screening programme as the immunised group would still be at risk from the oncogenic types not in the vaccine. What can be predicted is, that if vaccination is introduced the nature of screening will change both in terms of screening methods, with the use of molecular markers and HPV testing rather than cytology and microscopy, and the number of occasions on which women are screened.

\section{HUMAN PAPILLOMAVIRUS VACCINES IN THE DEVELOPING WORLD}

The results from the VLP vaccine trials are immensely encouraging and exciting but the great burden of cervix cancer is in women in 
the underdeveloped world and delivery of the HPV L1 vaccines to these women faces some major hurdles. Vaccines for these women must be cheap and easily delivered. The VLP vaccines will at least initially be expensive; thus the vaccine is not yet widely available but where it has been licensed the current price is over $\$ 100$ per dose (with three doses required to achieve full protection) although manufacturers have declared their willingness to tier prices for countries of different economic settings. The price at which the vaccine is available is almost certainly going to be a major determinant of the cost and affordability of any vaccine programme. Universal programmes for delivering health care to preadolescents are rare in the developing world, so the costs of establishing and maintaining a new system for HPV vaccination are likely to be considerable. Furthermore, social and cultural values in many countries will make vaccination of female adolescents extremely difficult. Infant vaccination reaches more than $70 \%$ of children in the world even in the poorest countries and realistically if HPV vaccines are to be delivered in such settings then it will be as infant vaccines. However, immunogenicity-bridging trials to support this have not been implemented.

An important issue is whether the $\mathrm{L} 1$ vaccines will both be, and remain, efficacious in immunocompromised subjects particularly those who are HIV infected. In developing countries, there is limited access to effective antiretroviral therapy raising questions of safety, immunogenicity and the induction of effective immune memory in such individuals. Clinical trials in HIV-infected individuals are underway but no data are available as yet, although one might predict that limited protection will be achieved in individuals with low T-cell counts.

\section{CONCLUSIONS}

The HPV L1 VLP vaccines are immensely important developments in public health and the benefits that they promise are immense, offering the opportunity to prevent, in the long term, $80 \%$ of cervical cancers, $60 \%$ of vulval and $90 \%$ of anal cancers in women. They will impact significantly in the short to medium term on the incidence of high-grade CIN reducing the number of women who have to undergo large loop excision of the transformation zone (LLETZ) and economically, in the long term, they will reduce health-care costs. But the overwhelming benefit is the major improvement for human health and well-being of women everywhere.

\section{REFERENCES}

af Geijersstam V, Eklund C, Wang Z, Sapp M, Schiller JT, Dillner J, Dillner L (1999) A survey of seroprevalence of human papillomavirus types 16, 18 and 33 among children. Int J Cancer 80: 489-493

Block SL, Nolan T, Sattler C, Barr E, Giacoletti KE, Marchant CD, Castellsague X, Rusche SA, Lukac S, Bryan JT, Cavanaugh Jr PF, Reisinger KS (2006) Comparison of the immunogenicity and reactogenicity of a prophylactic quadrivalent human papillomavirus (types 6,11 , 16 , and 18) L1 virus-like particle vaccine in male and female adolescents and young adult women. Pediatrics 118: $2135-2145$

Breitburd F, Kirnbauer R, Hubbert NL, Nonnenmacher B, Trin-DinhDesmarquet C, Orth G, Schiller JT, Lowy DR (1995) Immunization with virus-like particles from cotton tail rabbit papillomavirus (CRPV) can protect against experimentally CRPV infection. J Virol 69: 3959-3963

Carter JJ, Koutsky LA, Hughes JP, Lee SK, Kuypers J, Kiviat N, Galloway DA (2000) Comparison of human papillomavirus types 16, 18, and 6 capsid antibody responses following incident infection. J Infect Dis 181: $1911-1919$

Carter JJ, Wipf GC, Hagensee ME, McKnight B, Habel LA, Lee SK, Kuypers J, Kiviat N, Daling JR, Koutsky LA, Et A (1995) Use of human papillomavirus type 6 capsids to detect antibodies in people with genital warts. J Infect Dis 172: $11-18$

Chen XS, Garcea RL, Goldberg I, Casini G, Harrison SC (2000) Structure of small virus-like particles assembled from the L1 protein of human papillomavirus 16. Mol Cell 5: 557-567

Clifford G, Franceschi S, Diaz M, Munoz N, Villa LL (2006) Chapter 3: HPV type-distribution in women with and without cervical neoplastic diseases. Vaccine 24(Suppl 3): S26-S34

Clifford GM, Smith JS, Aguado T, Franceschi S (2003) Comparison of HPV type distribution in high-grade cervical lesions and cervical cancer: a meta-analysis. Br J Cancer 89: 101-105

Ghim S, Newsome J, Bell J, Sundberg JP, Schlegel R, Jenson AB (2000) Spontaneously regressing oral papillomas induce systemic antibodies that neutralize canine oral papillomavirus. Exp Mol Pathol 68: 147-151

Harper DM, Franco EL, Wheeler C, Ferris DG, Jenkins D, Schuind A, Zahaf T, Innis B, Naud P, De Carvalho NS, Roteli-Martins CM, Teixeira J, Blatter MM, Korn AP, Quint W, Dubin G (2004) Efficacy of a bivalent L1 virus-like particle vaccine in prevention of infection with human papillomavirus types 16 and 18 in young women: a randomised controlled trial. Lancet 364: 1757-1765

Harper DM, Franco EL, Wheeler CM, Moscicki AB, Romanowski B, RoteliMartins CM, Jenkins D, Schuind A, Costa Clemens SA, Dubin G (2006) Sustained efficacy up to 4.5 years of a bivalent L1 virus-like particle vaccine against human papillomavirus types 16 and 18: follow-up from a randomised control trial. Lancet 367: 1247-1255 http: www.cdc.gov/nip/acip/slides/jun06/hpv-2-barr.pdf

Jansen KU, Rosolowsky M, Schultz LD, Markus HZ, Cook JC, Donnelly JJ, Martinez D, Ellis RW, Shaw AR (1995) Vaccination with yeast expressed cottontail rabbit papillomavirus (CRPV) virus like particles protects rabbits from CRPV induced papilloma formation. Vaccine 13: $1509-1514$

Kirnbauer R, Booy F, Cheng N, Lowy DR, Schiller JT (1992) Papillomavirus L1 major capsid protein self assembles into virus like particles that are highly immunogenic. Proc Natl Acad Sci USA 89: 12180-12184

Kirnbauer R, Chandrachud LM, O'Neil BW, Wagner ER, Grindlay GJ, Armstrong A, McGarvie GM, Schiller JT, Lowy DR, Campo MS (1996) Virus-like particles of bovine papillomavirus type 4 in prophylactic and therapeutic immunization. Virology 219: 37-44

Mao C, Koutsky LA, Ault KA, Wheeler CM, Brown DR, Wiley DJ, Alvarez FB, Bautista OM, Jansen KU, Barr E (2006) Efficacy of human papillomavirus-16 vaccine to prevent cervical intraepithelial neoplasia: a randomized controlled trial. Obstet Gynecol 107: 18-27

Muñoz N, Castellsagué X, Barrington de González A, Gissmann L (2006) Chapter 1: HPV in the etiology of human cancer. Vaccine 24(Suppl 3): S1-S10

Nardelli Haefliger D, Wirthner D, Schiller JT, Lowy DR, Hildesheim A, Ponci F, De Grandi P (2003) Specific antibody levels at the cervix during the menstrual cycle of women vaccinated with human papillomavirus 16 virus-like particles. J Natl Cancer Inst 95: 1128-1137

Parkin DM, Bray F (2006) Chapter 2: The burden of HPV-related cancers. Vaccine 24(Suppl 3): S11-S25

Shope RE (1937) Immunization of rabbits to infectious papillomatosis. $J$ Exp Med 65: 607-624

Suzich JA, Ghim SJ, Palmer Hill FJ, White WI, Tamura JK, Bell JA, Newsome JA, Jenson AB, Schlegel R (1995) Systemic immunization with papillomavirus $\mathrm{Ll}$ protein completely prevents the development of viral mucosal papillomas. Proc Natl Acad Sci USA 92: 11553-11557

Villa LL, Costa RL, Petta CA, Andrade RP, Paavonen J, Iversen OE, Olsson SE, Hoye J, Steinwall M, Riis-Johannessen G, Andersson-Ellstrom A, Elfgren K, Krogh G, Lehtinen M, Malm C, Tamms GM, Giacoletti K, Lupinacci L, Railkar R, Taddeo FJ, Bryan J, Esser MT, Sings HL, Saah AJ, Barr E (2006) High sustained efficacy of a prophylactic quadrivalent human papillomavirus types 6/11/16/18 Ll virus-like particle vaccine through 5 years of follow-up. Br J Cancer 95: $1459-1466$

Walboomers JM, Jacobs MV, Manos MM, Bosch FX, Kummer JA, Shah KV, Snijders PJ, Peto J, Meijer CJ, Munoz N (1999) Human papillomavirus is a necessary cause of invasive cervical cancer worldwide. J Pathol 189: $12-19$ 